\title{
Conscientiousness in the Classroom: A Process Explanation
}

\author{
Katherine S. Corker, ${ }^{1}$ Frederick L. Oswald, ${ }^{2}$ and \\ M. Brent Donnellan ${ }^{3}$ \\ ${ }^{1}$ Kenyon College \\ ${ }^{2}$ Rice University \\ ${ }^{3}$ Michigon State University
}

\begin{abstract}
Although the research literature has established that Conscientiousness predicts task performance across a variety of achievement contexts (e.g., Barrick \& Mount, 1991; O’Connor \& Paunonen, 2007), comparatively less is known about the processes that underlie these relations. To the latter end, the current research examines effortful strategies and achievement goals as mediating factors that might explain why people with higher levels of Conscientiousness are predicted to reach higher levels of academic performance. In a longitudinal study, 347 college students completed measures of personality and achievement goals at the beginning of the class, followed by measures of effortful strategies multiple times throughout the semester. Results support the hypothesis that effortful strategies mediate the association between Conscientiousness and academic performance. Moreover, the statistical effects of Conscientiousness were generally independent of achievement goals, but a small portion of the effect was mediated through approach, not avoidance, achievement goals. These results highlight the importance of examining mediating processes between personality and outcomes, and in the case of Conscientiousness, our results suggest that effortful strategies might serve as a useful target for performance-enhancing interventions.
\end{abstract}

Intelligence and hard work are often viewed as two essential ingredients for success in achievement contexts such as school and work. Consistent with this intuition, there is a well-established literature

The authors thank Sara Jelinek, Kimberly Pingatore, and Jenna Kuhn for their assistance with data collection.

Correspondence concerning this article should be addressed to Katherine S. Corker, Samuel Mather Hall, Kenyon College, Gambier, OH 43022. Email: corkerk@ kenyon.edu.

Journal of Personality 80:4, August 2012

(C) 2011 The Authors

Journal of Personality (C) 2011, Wiley Periodicals, Inc.

DOI: $10.1111 / \mathrm{j} .1467-6494.2011 .00750 . x$ 
focusing on the connections between intelligence and performance (e.g., Judge, Higgins, Thoresen, \& Barrick, 1999; Schmidt \& Hunter, 1998), and a more recent history of research has pointed to the importance of Conscientiousness as a predictor of job performance that is relatively independent of intelligence (e.g., Barrick \& Mount, 1991; Judge et al.,1999; Judge, Klinger, Simon, \& Yang, 2008; Noftle \& Robins, 2007; Roberts, Kuncel, Shiner, Caspi, \& Goldberg, 2007). Turning to the academic context, a recent meta-analysis found that Conscientiousness, in fact, was the only practically significant personality predictor of postsecondary performance (O'Connor \& Paunonen, 2007). Additional research is now required to understand why Conscientiousness predicts outcomes by identifying and modeling the mediating mechanisms between Conscientiousness and academic performance outcomes. In the current study, we propose that Conscientiousness is related to the types of goals, study strategies, and work habits that in turn promote success in academic contexts. We test this proposed process-based explanation using longitudinal data collected from college students.

Our perspective is informed by McAdams and Pals's (2006) integrative personality framework, which identifies three major levels of personality. The first level, dispositional traits, is probably the most dominant approach in contemporary personality psychology. This level captures "broad individual differences in behavior, thought, and feeling that account for general consistencies across situations and over time" (p. 212). The second level, characteristic adaptations, incorporates social-cognitive variables such as goals that are "contextualized in time, situations, and social roles" (p. 212). The third and most fine-grained level addresses life narratives, or the construction of life stories and the development of individual identities. Our investigation focuses on the first two levels, in that we use constructs from the achievement goal literature to help explain how Conscientiousness (a dispositional or trait construct) is linked with academic outcomes. Formulating process models that bridge these two levels provides an opportunity to develop a more integrative understanding by moving beyond the study of simple trait-to-outcome correlations in the domains of personality and educational research.

\section{Conceptualizing Conscientiousness}

The Big Five taxonomy is currently the most popular framework for organizing the many personality traits studied by personality 
researchers (Roberts et al., 2007). Within the Big Five, Conscientiousness captures individual differences in "socially prescribed impulse control that facilitates task- and goal-directed behavior, such as thinking before acting, delaying gratification, following norms and rules, and planning, organizing, and prioritizing tasks" (John, Naumann, \& Soto, 2008, p. 120). A key element of modern trait approaches is the idea that individual differences in the Big Five domains are relatively stable (especially over the short term, such as an academic semester) and that they are rooted, at least in part, in temperament and biological differences between individuals (see McCrae \& Costa, 2008). Indeed, Conscientiousness is associated with the temperamental domain of effortful control (Kochanska \& Knaack, 2003) and also with a suite of constructs associated with higher-order thinking, including executive functioning, working memory capacity, and differences in brain activity related to the prefrontal cortex (DeYoung et al., 2010; Hofmann, Gschwendner, Friese, Wiers, \& Schmitt, 2008; Nigg, 2000). In short, there is evidence in support of the cognitive and neurobiological underpinnings for individual differences in Conscientiousness.

Previous research has demonstrated an association between Conscientiousness and academic performance. For example, Noftle and Robins (2007) found that Conscientiousness predicted college grade point average (GPA) across four different samples and with four different measures of Conscientiousness. O'Connor and Paunonen (2007) conducted a meta-analysis that summarized the literature correlating Conscientiousness with measures of academic performance such as grades. Across studies, Conscientiousness was a robust predictor of overall GPA (i.e., average $r=.25$; $k=16$ ).

It is worth noting that Conscientiousness is a broad personality domain that encompasses several narrower and more specific dimensions, often called facets. These narrower dimensions of personality may have stronger or weaker correlations with outcomes such as academic performance, compared with the overall associations reported for summary measures of Conscientiousness. For instance, Paunonen and Ashton (2001) investigated the association between the facets of Conscientiousness as measured by the Personality Research Form scales (PRF; Jackson, 1984) and students' final course grades. They found that their Conscientiousness composite composed of six facets (Achievement, Cognitive Structure, Desirability, Endurance, Order, and negative Impulsivity) showed a posi- 
tive correlation with course grades but that there were meaningful differences in the level of prediction for each facet. Specifically, most of the statistically significant effects were carried by the Achievement facet, a dimension capturing motivation to accomplish high levels of performance. In contrast, the Order facet, which assesses tendencies to be neat and tidy, did not significantly predict performance. Similarly, Noftle and Robins (2007) found that the Achievement Striving facet of the NEO Personality Inventory-Revised (NEO-PI-R; Costa $\&$ McCrae, 1992) predicted college GPA slightly better than a Conscientiousness composite, whereas the Order facet was not predictive of GPA.

Thus, some previous research has shown that facet-level analyses can provide more precise information about predictor-criterion associations involving Conscientiousness. To be sure, there is a longstanding discussion about the relative utility of broad versus narrow personality constructs and measures in the literature (cf. de Vries, de Vries, \& Born, 2010; Ones \& Viswesvaran, 1996). One argument favoring studies that focus on narrower attributes is that they can provide better insight into why broader attributes like Conscientiousness are linked with performance (de Vries et al., 2010). This level of analysis is useful, given our own focus on the precise mechanisms involving effort and perseverance that link Conscientiousness to academic outcomes.

\section{Effort as Mediator of Associations Between Conscientiousness and Outcomes}

In terms of concrete behavioral mediators, there is good reason to expect that effort and perseverance are important explanatory mediators between Conscientiousness and performance outcomes like GPA. For example, Noftle and Robins (2007) found that academic effort mediated the association between Conscientiousness and college GPA. Duckworth and Seligman (2005) found that SelfDiscipline (a facet of Conscientiousness) was positively associated with number of hours spent on homework and negatively associated with absences from school, both of which can be conceptualized as indicators of effort that in turn affect academic performance. Trautwein, Lüdtke, Roberts, Schnyder, and Niggli (2009) showed that Conscientiousness predicted academic effort in math and English in two samples of German eighth graders. In the second sample, they also showed that effort mediated the association between Conscien- 
tiousness and math grades (controlling for prior math achievement). In short, effort and task persistence are likely to be key mediators of the association between Conscientiousness and academic outcomes in college students.

To be sure, a number of studies that did not specifically investigate the role of personality have supported the relationship between effort and task performance. For example, Keith and Cool (1992) found that "motivation" (operationalized as self-reported willingness to persevere on tasks) was positively associated with standardized achievement test scores $(r=.26)$ in the High School and Beyond dataset. Staff, Schulenberg, and Bachman (2010) found that effort exerted in school (operationalized as the frequency that a student tried to do his or her best work) positively predicted high school GPA $(r=.36)$ in the Monitoring the Future study. Keith, DiamondHallam, and Fine (2004) found that time spent doing homework was positively associated with high school grades ( $r$ s ranged from .20 to .31). Likewise, a recent meta-analysis showed similar effects (e.g., $r=.14$ between time spent on homework and grades; Cooper, Robinson, \& Patall, 2006). Thus, there is a wealth of empirical support for a positive relationship between effort and academic success, and we extend this support within a theoretical model that integrates personality with effort-related processes that lead to academic outcomes.

\section{Conscientiousness and Achievement Goals}

Effort is only one of the mechanisms by which Conscientiousness may predict academic performance outcomes. Another potential mechanism involves achievement goal orientations, or how individuals construe achievement-related contexts. Achievement goals have been invoked as a key explanatory variable in social-cognitive approaches to understanding how personality is associated with achievement (cf. Dweck \& Leggett, 1988), and achievement goals have been the subject of considerable research in educational, developmental, and social psychology (e.g., Elliot \& Thrash, 2010). Elliot's $2 \times 2$ model (Elliot \& McGregor, 2001) considers four relatively distinct achievement goal orientations: performance approach, performance avoidance, mastery approach, and mastery avoidance. Individuals with mastery goals are striving to learn and develop competence (mastery approach) or to avoid failing to learn (mastery avoidance), whereas individuals with performance goals are striving 
to demonstrate competence (performance approach) or avoid revealing incompetency (performance avoidance). In general, regardless of whether a mastery or performance orientation is taken, approachoriented achievement goals tend to predict higher levels of performance, whereas avoidance-oriented achievement goals predict lower levels of performance (Elliot \& McGregor, 2001).

There have also been attempts to connect biologically based individual difference constructs to performance outcomes via achievement goal orientations (e.g., Elliot \& Church, 1997; Elliot \& Thrash, 2002) in line with the general perspective outlined in the McAdams and Pals (2006) model. According to Elliot's hierarchical model of motivation (Elliot, 2006; Elliot \& Thrash, 2010), people with approach temperaments (variously defined as those with higher levels of Extraversion, positive emotionality, or the behavioral activation system) tend to adopt more approach-oriented achievement goals, whereas those with avoidance temperaments (variously defined as those with higher levels of Neuroticism, negative emotionality, or the behavioral inhibition system) adopt more avoidanceoriented achievement goals (Elliot \& Thrash, 2010). The model assumes that goals are derived from temperamentally based traits but are not completely subsumed by them. Traits are relatively stable, context-free, and biologically based, whereas goals are more defined and influenced by the situational context. Of note is the fact that the hierarchical model does not currently specify a clear role for Conscientiousness; however, it may be useful to integrate Conscientiousness into the hierarchical model given the importance of this disposition for achievement outcomes.

Consistent with our emphasis on connecting trait-related work with more proximal social-cognitive constructs, researchers have found preliminary evidence for the role of goals as mediators of the Conscientiousness-to-performance effect in work settings. For example, Barrick, Stewart, and Piotrowski (2002) found that the effect of Conscientiousness on performance in a sales job was mediated by two social-cognitive variables: accomplishment striving and status striving. Respectively, these variables reflect the degree to which individuals have a high achievement orientation and have the goal of achieving high status among their coworkers or in their profession. Importantly these mediating variables explain why Conscientiousness is related to performance, not merely that it is related to performance-namely, Conscientious people are better perform- 
ers because they tend to want to accomplish tasks and gain respect within their profession. In a similar vein, we propose that in the academic context, Conscientiousness predicts increased effort (and ultimately performance) independently and through achievement goals, as displayed in Figure 1.

It may also be the case that Conscientiousness predicts certain achievement goals that themselves predict more proximal behaviors that facilitate high academic performance (e.g., high levels of effort, proactive study strategies). Previous research has shown that Conscientiousness has moderate positive associations with mastery approach goals (sample-weighted mean $r=.26$ ) and weaker associations with performance avoidance goals (sample-weighted mean $r=-.14$; Payne, Youngcourt, \& Beaubien, 2007). But it could also be the case that Conscientiousness functions in parallel with achievement goals, predicting behaviors that facilitate high performance independent of any associations with achievement goals (cf. Charmorro-Premuzic \& Furnham, 2003). Thus, it is possible that both Conscientiousness and achievement goals operate relatively independently of each other. Given these inconsistencies and competing predictions, more research is needed to clarify how Conscientiousness is related to achievement goals and the behaviors that predict success in achievement settings.

\section{The Current Study and Specific Predictions}

In sum, there are two major objectives of the present study. First, we extend the literature relating specific facets of Conscientiousness to academic performance. Specifically, we predicted that Self-Discipline and Achievement Striving, reflecting an increased propensity for task persistence and effort, are the two major facets of Conscientiousness that should be largely responsible for association between Conscientiousness and academic outcomes. Further, we expected that these associations would be independent of cognitive ability and the other Big Five personality factors. Second, we tested a specific processbased model relating Conscientiousness to outcomes by way of two proximal mediators implicated by theory: effort and achievement goals. We tested this model by using students' personalities and goals (relatively distal predictors) as statistical predictors of effort and study strategies (proximal mediating factors) that in turn were posited to predict performance outcomes (see Figure 1). Finally, we assessed academic achievement outcomes (total course grade, exam 


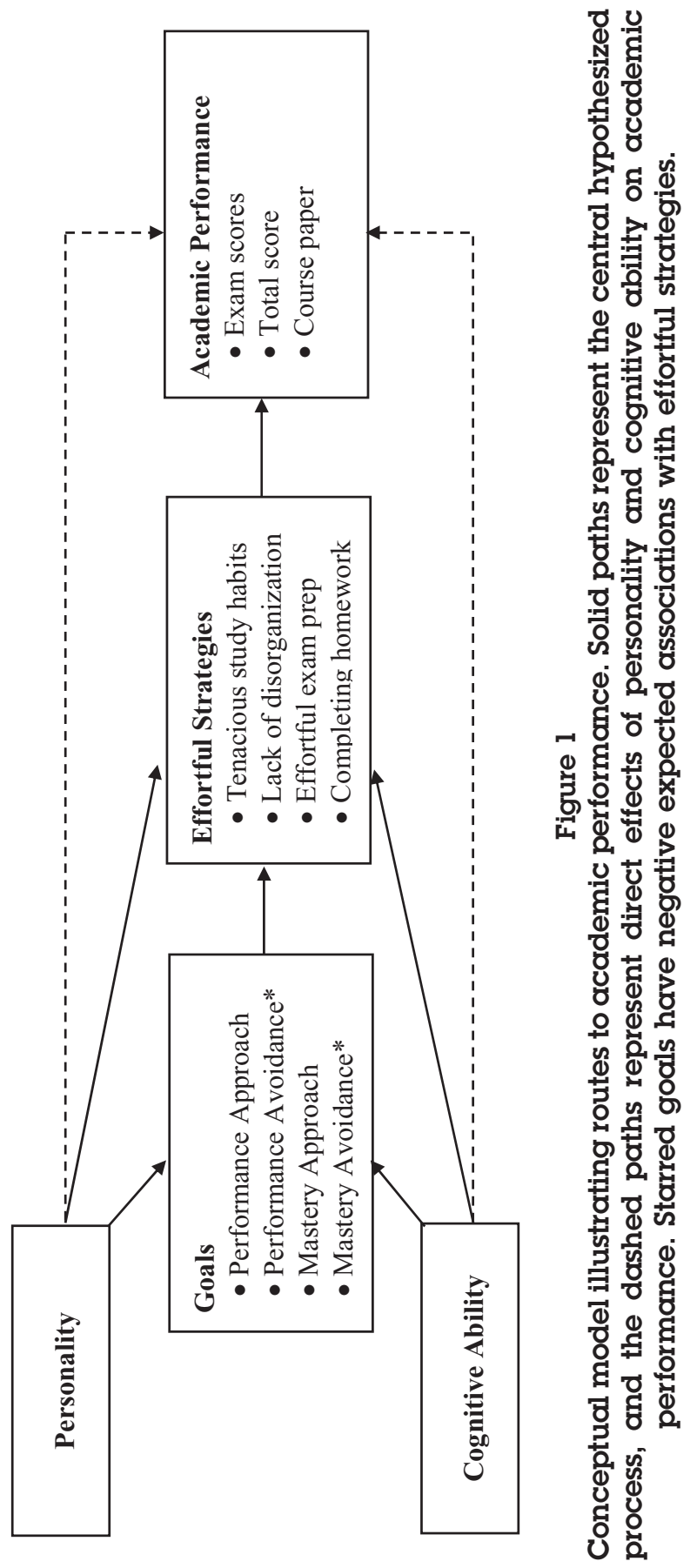


grades, course paper scores) with a variety of behavioral and selfreport assessments. O'Connor and Paunonen (2007) lamented that relatively few studies used multiple measures of achievement in the academic domain:

Most studies have employed a single overall indicator of scholastic achievement as the criterion measure of academic performance, grade point average being the favorite. However, academic performance is not a unitary construct.... Thus, investigators are strongly encouraged to examine specific components of academic performance, as well as overall indicators of academic success, in future investigations. (O’Connor \& Paunonen, 2007, p. 986)

Empirical support for our model is therefore not predicated on a single measure or outcome. Instead, we attempt to find support for our predicted effects in the context of a general theoretical model that goes well beyond the scope of constructs assessed in most previous research.

\section{METHOD}

\section{Participants and Procedure}

Participants were recruited from a one-semester psychological research methods course required of all psychology majors at a large Midwestern research university. Data were collected during two semesters of the course (Fall 2008 and Spring 2009), and students received extra course credit for participating either in this study or other research alternatives of their choosing. Of 446 eligible students, 347 enrolled and consented to participate (78\% participation rate). Participants were primarily juniors and seniors $(90 \%)$, White $(82 \%)$, and female $(76 \%)$.

Participants were recruited for the study on the first day of class, at which time they were informed that although some of the data collection would take place during class, their status as a participant or a nonparticipant would not be made known to the instructor and would have no impact on their grades in the class; students gave additional consent to release their course grades to the researchers. The first author, who was not affiliated with the course, collected the data while the instructor was absent. The research was approved by the local Institutional Review Board, and the instructor was blind to participation until the end of the respective semester. 
On the first day of class, after agreeing to participate in the study, participants received a baseline questionnaire packet that they completed at home and returned on the second day of class. The baseline questionnaire packet contained demographic questions and the personality and achievement goal measures. In the week prior to the first exam, another assessment was administered in class, assessing study strategies specific to the research methods course. Directly after each of the three exams, participants completed a short questionnaire that asked about the effort that they put into preparing for the exam. At the conclusion of the course, participants' grades (including total points earned, exam scores, homework scores, and course paper scores) were obtained from course records.

\section{Materials}

Descriptive statistics, alpha reliabilities, and zero-order correlations with course outcomes for study variables are reported in Table 1 . The appendix reports correlations between predictor variables. All self-report personality, goal, strategy, and effort measures used a 1 to 5 scale (strongly disagree to strongly agree).

Personality and cognitive ability. Because we were interested specifically in Conscientiousness as a predictor of academic performance, we assessed Conscientiousness at the detailed facet level using 60 items from the 300-item form of the International Personality Item Pool (IPIP; Goldberg, 1999). These items assess six Conscientiousness facets (Self-Efficacy, Orderliness, Dutifulness, Achievement Striving, Self-Discipline, and Cautiousness) with 10 items each. The other Big Five domains of Openness, Emotional Stability, Extraversion, and Agreeableness were assessed more broadly at the level of their general factor (not facets); therefore, we used the 10 -item scales from the 50 -item form of the IPIP. Alpha reliabilities for the factors and facets were consistent with previous studies ( $\alpha \mathrm{s}=.78$ to .95 for factors and .76 to .90 for facets). All personality measures were administered at the beginning of the study.

Cognitive ability was measured by self-reported ACT score. The ACT is a standardized achievement test required for college admission; it is the preferred test at the university where the research was conducted. The median reliability of the ACT is .95 (ACT, 2007). Further, the correlation between self-reported ACT score and score obtained from university officials in a large $(N=16,643)$ recent study was $r=.95$ (J. S. Cole \& Gonyea, 2010), suggesting that self-reported ACT scores, though not perfect, are probably sufficiently reliable and predictive of actual ACT scores for research purposes. We included ACT score in our analyses because we 
Table 1

Descriptive Statistics and Zero-Order Correlations

\begin{tabular}{|c|c|c|c|c|c|c|c|c|}
\hline & \multicolumn{3}{|c|}{$\begin{array}{l}\text { Descriptive } \\
\text { Statistics }\end{array}$} & \multicolumn{5}{|c|}{ Correlations } \\
\hline & $M$ & $S D$ & $\alpha$ & $\begin{array}{c}\text { Total } \\
\text { Points } \\
(n=344)\end{array}$ & $\begin{array}{c}\text { Exam } \\
\text { Avg. } \\
(n=343)\end{array}$ & $\begin{array}{c}\text { Course } \\
\text { Paper } \\
(n=325)\end{array}$ & $\begin{array}{c}\text { HW } \\
(n=344)\end{array}$ & $\begin{array}{c}\text { Exam } \\
\text { Effort } \\
(n=296)\end{array}$ \\
\hline \multicolumn{9}{|l|}{ Personality/Ability } \\
\hline 1. Conscientiousness & 3.71 & .46 & .95 & .20 & .10 & .09 & .19 & .27 \\
\hline a. Self-Efficacy & 3.82 & .41 & .78 & $.15_{b}$ & $.10_{\mathrm{ab}}$ & $.07_{\mathrm{ab}}$ & $.14_{b}$ & $.18_{\mathrm{b}}$ \\
\hline b. Orderliness & 3.66 & .70 & .86 & $.06_{\mathrm{c}}$ & $-.04_{c}$ & $.01_{\mathrm{b}}$ & $.10_{\mathrm{b}}$ & $.11_{\mathrm{b}}$ \\
\hline c. Dutifulness & 4.11 & .47 & .76 & $.10_{\mathrm{b}}$ & $.01_{\mathrm{bc}}$ & $.03_{\mathrm{ab}}$ & $.12_{b}$ & $.16_{b}$ \\
\hline d. Achievement & 3.91 & .58 & .86 & $.15_{b}$ & $.10_{\mathrm{ab}}$ & $.06_{\mathrm{ab}}$ & $.14_{b}$ & $.30 \mathrm{a}$ \\
\hline e. Self-Discipline & 3.28 & .73 & .90 & $.28_{\mathrm{a}}$ & $.14_{\mathrm{ab}}$ & $.13_{\mathrm{a}}$ & $.26_{a}$ & $.33_{a}$ \\
\hline f. Cautiousness & 3.39 & .63 & .83 & $.19_{\mathrm{ab}}$ & $.16_{a}$ & $.09_{\mathrm{ab}}$ & $.14_{b}$ & $.16_{b}$ \\
\hline 2. Extraversion & 3.38 & .76 & .89 & .03 & -.06 & -.02 & .01 & .08 \\
\hline 3. Agreeableness & 4.15 & .49 & .78 & .06 & .02 & .04 & .04 & .08 \\
\hline 4. Neuroticism & 3.01 & .73 & .86 & -.04 & -.10 & .07 & -.06 & -.08 \\
\hline 5. Openness & 3.70 & .57 & .80 & .08 & .11 & .02 & -.04 & -.07 \\
\hline 6. Cognitive ability & 24.82 & 3.25 & - & .17 & .27 & .16 & .05 & -.07 \\
\hline \multicolumn{9}{|l|}{ Study strategies } \\
\hline 7. Surface processing & 3.59 & .67 & .69 & .12 & .05 & .19 & .17 & .23 \\
\hline 8. Deep processing & 2.89 & .72 & .74 & .09 & .12 & .00 & .08 & .15 \\
\hline 9. Tenacity & 3.52 & .72 & .86 & .29 & .28 & .11 & .25 & .56 \\
\hline 10. Disorganization & 2.55 & .94 & .88 & -.32 & -.36 & -.11 & -.14 & -.13 \\
\hline \multicolumn{9}{|l|}{ Achievement goals } \\
\hline 11. Perf. approach & 3.18 & 1.07 & .88 & .21 & .21 & .14 & .24 & .12 \\
\hline 12. Perf. avoidance & 3.77 & .89 & .72 & -.08 & -.13 & -.04 & -.04 & .01 \\
\hline 13. Mastery approach & 3.83 & .74 & .78 & .09 & .11 & .03 & .12 & .27 \\
\hline 14. Mastery avoidance & 3.00 & .87 & .78 & -.01 & -.03 & -.03 & .06 & .01 \\
\hline \multicolumn{9}{|l|}{ Course measures } \\
\hline 15. Total points & 408.16 & 74.23 & - & - & & & & \\
\hline 16. Exam average & 75.95 & 10.97 & .79 & .79 & - & & & \\
\hline 17. Course paper & 102.06 & 19.44 & - & .75 & .35 & - & & \\
\hline 18. Homework points & 70.82 & 13.82 & - & .77 & .48 & .59 & - & \\
\hline 19. Exam effort & 3.11 & .88 & .67 & .32 & .29 & .09 & .25 & - \\
\hline
\end{tabular}

Note. $\mathrm{HW}=$ homework points; Perf. $=$ performance. Boldfaced correlations are statistically significant $(p<.05)$. Facets not sharing the same subscript in the same column (i.e., for the same outcome variable) are statistically different from one another.

were sensitive to the fact that cognitive ability is a potentially important predictor of academic outcomes. Thus, we wanted to address this "third variable" possibility. However, none of the presented analyses changed in a substantial way when ACT scores were excluded from the analyses.

Achievement goals. Achievement goals were measured at the beginning of the study using the Achievement Goals Questionnaire (AGQ; Elliot \& 
McGregor, 2001), which is composed of 12 items, with three items per subscale. The subscales assess students' goals categorized by mastery approach (e.g., "I want to learn as much as possible from this class"), mastery avoidance (e.g., "I worry that I may not learn all that I possibly could in this class"), performance approach (e.g., "It is important for me to do better than other students"), and performance avoidance (e.g., "My goal in this class is to avoid performing poorly"). Alpha reliabilities were consistent with previous studies ( $\alpha \mathrm{s}=.72$ to .88 ).

Study strategies. Course-specific study strategies were assessed in class the week before the first exam using the 21-item study strategies questionnaire (Elliot, McGregor, \& Gable, 1999). The measure is composed of scales assessing deep processing (five items; $\alpha=.74$, e.g., "I try to think through topics and decide what I'm supposed to learn from them, rather than studying topics by just reading them over"), surface processing (five items; $\alpha=.69$, e.g., "When I study for the exam, I try to memorize as many facts as I can"), disorganization (five items, $\alpha=.88$, e.g., "I'm not sure how to study for this course"), persistence (four items; $\alpha=.81$, e.g., "Regardless of whether or not I like the material, I work my hardest to learn it"), and effort (two items; $\alpha=.86$, e.g., "I worked very hard to prepare for the exam"). On the basis of an exploratory factor analysis of these scales, we combined the persistence and effort scales into a single scale called "tenacity," as the item factor loadings for these two scales were suggestive of a single factor, and the bivariate correlation between the two scales $(r=.68)$ further justified combining them (for tenacity, $\alpha=.86$ ).

Effort. Following each of the three exams, we assessed self-perceived exam effort using the two-item effort subscale of the study strategies questionnaire (Elliot, McGregor, \& Gable, 1999), which we modified slightly to make the items pertain specifically to the current exam situation (i.e., "I put a lot of effort into preparing for this exam" and "I worked very hard to prepare for this exam"). These items are distinct from the Conscientiousness items at a conceptual level because they refer to specific exam settings rather than general behavioral tendencies. Furthermore, they are distinct empirically: A confirmatory factor analysis with two separate factors for exam effort and Conscientiousness fit the data well, $\chi^{2}(8)=11.55, p=.172, \mathrm{CFI}=1.00, \mathrm{RMSEA}=.036$, SRMR $=.025$, and significantly better than an analysis with one factor accounting for both, $\Delta \chi^{2}(1)=117.03, p<.001$.

The means of these scales were comparable across the three waves $(M \mathrm{~s}=3.14,3.08,3.12 ; S D \mathrm{~s}=1.06,1.13,1.10$; all $d$ values $<.06)$, and the alpha reliabilities were high $(\alpha=.93, .94, .93)$. In structural equation models, we treat the measure of effort at each occasion as an indicator of 
a latent exam effort variable, and for analyses using multiple regression, we average all six items (two items per occasion for three occasions) into an exam effort scale $(\alpha=.85)$. The average stability coefficient across adjacent waves was $r=.41$, explaining the decrease in alpha reliability from the two-item to the six-item scales.

We further operationalized effort using scores on homework assignments. Homework scores are a good behavioral indicator of effort in this research methods course for at least two reasons. First, students had to remember to complete their homework assignments and submit them to their lab instructors in class on the due date in order to receive a grade. As expected, lab attendance (measured as the proportion of 10 labs attended) ${ }^{1}$ and homework scores were strongly correlated $(r=.57)$, suggesting that a sizable portion of variance in students' homework grades was associated with merely showing up to submit it. This claim is further supported by the fact that when controlling for exam performance, the partial correlation between lab attendance and homework scores decreased very slightly to $r=.55$, implying that homework grades were measuring effort, not learning. Second, the assignments were awarded partial credit, such that variation in homework effort would be reflected in variations in grades. It should be noted that the course records available only contained data on aggregated homework scores (i.e., number of points earned out of 80 possible), rather than scores for each of the eight individual homework assignments. Thus, homework scores are always incorporated as a single observed variable in the structural equation modeling (SEM) analyses. ${ }^{2}$

Academic performance. Performance in the research methods course was measured on a 500-point scale, with 300 points $(60 \%)$ attributable to three 100 -point, multiple-choice exams, 120 points $(24 \%)$ attributable to the course paper, and 80 points $(16 \%)$ attributable to homework. Up to 30 points of extra credit were permitted ( 20 points from completing research studies or writing journal article summaries and 10 points from completing an optional extra homework assignment), which were added to the total course points earned and impacted the final grade. As can be seen, the exams, course paper, and homework are all components that contrib-

1. Two of nine lab instructors (i.e., teaching assistants) did not collect attendance data on their students; thus, attendance data are missing for these 76 participants. Additionally, two lab instructors did not take attendance for 1 of their 10 labs. For the participants in those lab sections $(n=41)$, we used the percentage of labs attended for the nine lab periods in which we had data as the attendance measure. 2. This strategy was necessary but precludes an assessment of the reliability of homework scores. However, in the same course taught by the same instructor during a different semester, the alpha reliability for the homework assignments from two laboratory sections was found to be approximately .90 . 
ute meaningfully to the final grade. The contribution of these components to the final grade is not a direct function of the points awarded, however, because the components themselves have different standard deviations and are also differentially correlated with one another. For this reason, components are treated separately as well as together.

\section{ANALYSES AND RESULTS}

Missing data are dispersed throughout the dataset; however, over $95 \%$ of participants completed at least three of the waves of data collection, $92 \%$ completed at least four waves, and $80 \%$ completed all five waves. For the analyses that use structural equation modeling, we used full information maximum likelihood (FIML) to account for missing data. This is one of the recommended methods for handling missing data according to Widaman (2006), assuming the data are missing at random (an assumption that is difficult to test but is easier to accept given the amount of missing data is limited as in our case). For these models, the full sample $(N=347)$ is analyzed using Mplus (Version 4.1; Muthén \& Muthén, 1998-2006). All other analyses use listwise deletion of missing data, with adjusted sample sizes reported throughout the text and tables. ${ }^{3}$ All mediational analyses used a recommended bias-corrected bootstrapping technique with 5,000 resamples (see MacKinnon, Fairchild, \& Fritz, 2007).

\section{Preliminary Correlational Analyses}

We first investigated the zero-order correlations between our personality predictors, three performance outcomes (total course points, exam average, course paper score), and two types of effort (homework scores and average exam effort). Table 1 shows that Conscien-

3. It could be argued that all of our statistical analyses should be conducted using the FIML estimation technique to correct for the influence of missing data. Path analyses conducted using FIML functioned nearly identically to the presented multiple regression analyses using listwise deletion, with two exceptions. In the analysis predicting exam effort from the Big Five and ACT score, the predictive validity of Openness increased slightly from $\beta=-.12$ to $\beta=-.18$, whereas the coefficient for Conscientiousness decreased slightly from $\beta=.29$ to $\beta=.23$. In the analysis predicting average exam score from the facets of Conscientiousness and ACT score, the predictive validity of Dutifulness increased from $\beta=-.06$ to $\beta=-.17$, and the coefficient for Self-Discipline decreased from $\beta=.20$ to $\beta=.13$. On the whole, these variations from the results we present are relatively minor. 
tiousness had larger correlations with all five outcomes compared with the other Big Five domains ( $r$ s ranged from .09 to .27). Three of the five Conscientiousness correlations were statistically significant. By contrast, of the 20 possible correlations between Extraversion, Agreeableness, Neuroticism, and Openness and the five course outcomes, only one correlation was statistically different from zero, and its magnitude was .11, on the low end of the distribution of the validity coefficients for Conscientiousness. ${ }^{4}$ Further, only one significant correlation would be predicted by Type I error if the critical region for significance tests (alpha) were set to .05.

Regarding the correlations between the individual facets of Conscientiousness and outcomes, Self-Discipline appeared to be the most consistent predictor of all five academic outcomes ( $r$ s ranged from .12 to .28). Orderliness, in contrast, was only associated with exam effort $(r=.11)$. The magnitude of the coefficients for the other four facets was somewhere in between, with Cautiousness significantly predicting four outcomes (significant $r$ s ranged from .14 to .19), Achievement Striving predicting three outcomes (significant $r \mathrm{~s}$ ranged from .14 to .30), Self-Efficacy predicting three outcomes (significant $r$ s ranged from .14 to .18), and Dutifulness predicting two outcomes (significant $r$ s ranged from .12 to .16).

We conducted an exploratory analysis that statistically compared the size of these various facet to outcome correlations using a test of dependent correlations. As indicated in Table 1, the analysis revealed that Self-Discipline had larger correlations than the majority of the other facets with three of the outcomes. Specifically, Self-Discipline had larger correlations with homework scores than the other five facets, and it also had larger correlations with total points than all of the other facets except for Cautiousness. Self-Discipline and Achievement Striving were statistically equal and had larger associations with exam effort than the other three facets. The results for the other two outcomes were more mixed. Self-Discipline's association with the course paper grade was larger only than Orderliness's asso-

4. Note that reliability coefficients of these four factors were slightly lower than the reliability of Conscientiousness, ranging from .78 to .89 versus .95 for Conscientiousness, but this difference is not large enough to suggest there is a stronger attenuation effect for the non-Conscientiousness traits due to greater measurement error variance in the trait measures. Correcting all zero-order correlations for measurement unreliability in their respective personality measures led to a minimal correction effect and therefore the same substantive conclusions. 
ciation. Self-Discipline, Cautiousness, Achievement Striving, and Self-Efficacy all had larger associations with exam scores than Orderliness but were statistically equivalent to one another in the magnitude of their associations with exam scores.

\section{Independent Effects of Personality on Course Outcomes}

Broad domains. To examine the independent effects of each of the Big Five factors on performance outcomes (total points earned, exam scores, and course paper scores) and effort (homework scores and exam effort), we conducted hierarchical multiple regressions predicting each of the three course outcomes and two effort variables. In Step 1 of each analysis, we entered ACT score alone to determine how much variance is accounted for by a measure of cognitive ability; then in Step 2, we entered the Big Five factors simultaneously. As displayed in the top panel of Table 2, Conscientiousness positively and significantly predicted each of the five outcome variables ( $\beta$ s ranged from .13 to .29), independent of the other personality factors. The only other statistically significant personality effect was a positive independent effect for Neuroticism predicting the course paper score $(\beta=.14)$.

Facet-level analyses. We also conducted regression analyses to evaluate the unique contributions (if any) of the individual facets of Conscientiousness to these five outcome variables. As shown in the top panel of Table 2, the Self-Discipline facet emerged as the only unique predictor of course performance, with significant positive associations with all three performance outcomes ( $\beta$ s ranging from .19 to .37). Self-Discipline also uniquely predicted homework scores $(\beta=.31)$, and both Self-Discipline and Achievement Striving uniquely predicted exam effort ( $\beta \mathrm{s}=.25$ and .26 , respectively). In general, these results parallel the analyses described previously comparing the size of the bivariate associations between facets and outcomes. Using either methodology, Self-Discipline emerged as the most consistent facet-level predictor of outcomes.

\section{Mediators of the Association Between Personality and Course Outcomes}

To evaluate the process by which Conscientiousness is associated with differences in course outcomes, we first conducted a series of 


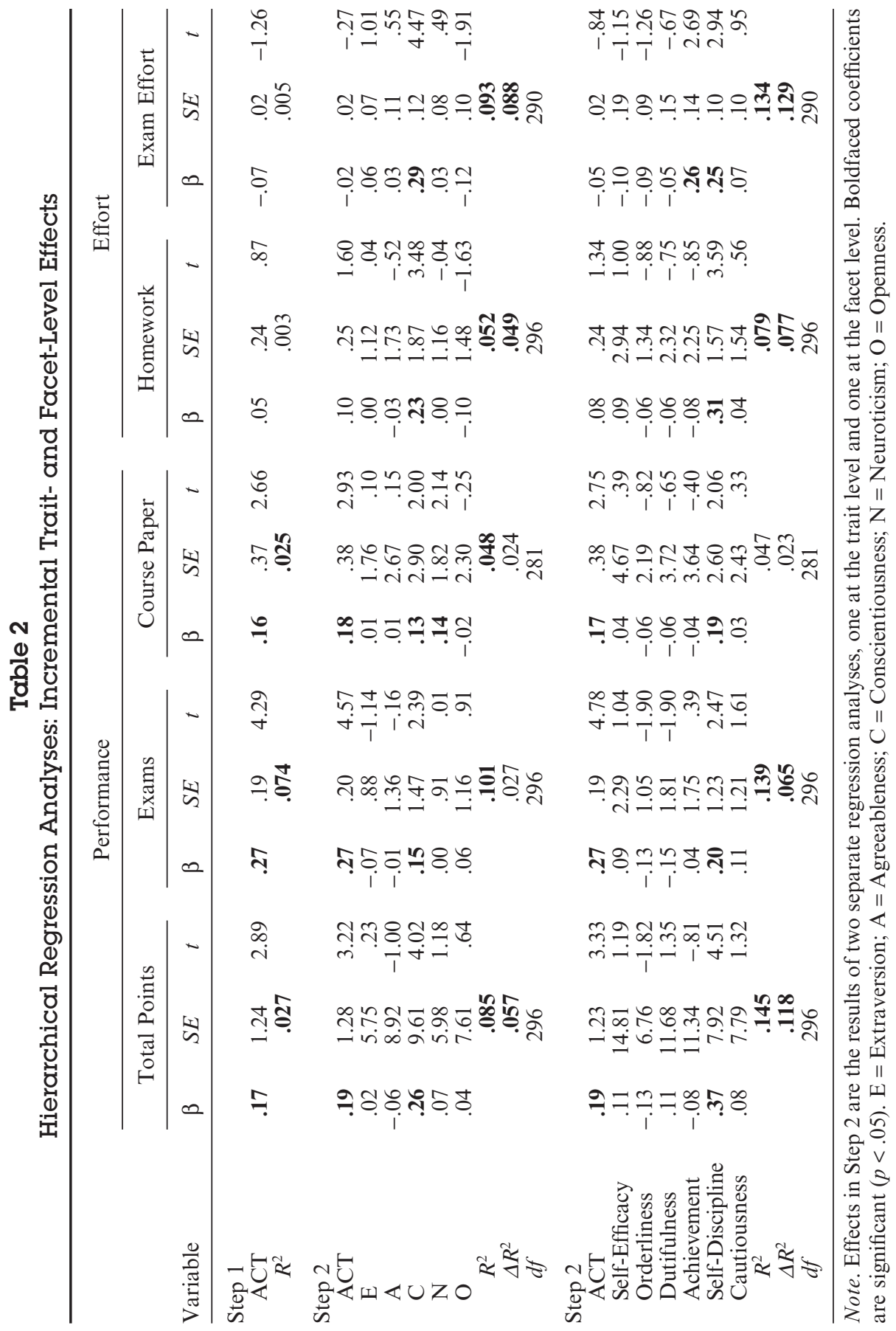


structural equation models with self-reported effort for exam preparation, homework scores, and study strategies as the proposed mediators. We then extended these basic mediational analyses to examine the role of achievement goals in this process (see Figure 1). In all analyses, we included self-reported ACT scores to estimate statistical effects that are independent of general cognitive ability. Conscientiousness was measured by 60 items; we therefore created three parcels of 20 items each by randomly assigning items to parcels, and these parcels served as three indicators for the latent Conscientiousness variable. Assuming unidimensionality of the constituent items, parcels result in more stable parameter estimates than individual items because error variances of the parcels are more likely to be normally distributed, and fewer parameters have to be estimated (Kishton \& Widaman, 1994). The parceling technique has been used in research of a similar nature (e.g., Trautwein et al., 2009). We modeled achievement goals using the three items from each subscale as individual indicators of that subscale. However, we opted to model study strategies at the observed scale level because the scale length made parceling difficult, and the scales were measured at a fairly high level of reliability (see Table 1). Furthermore, the general conclusions for structural results do not change if we conduct a more complex latent modeling approach with five or six individual items as indicators for these scales.

Mediation by effort. Figure 2 displays the results of a structural equation model relating Conscientiousness to exam scores via selfreported effort in preparing for each exam. ${ }^{5}$ A latent Effort construct uses self-reported assessments of effort exerted in preparing for each of the three exams as indicators; similarly, a latent Exam Score construct was indicated by the three exam scores as indicators. Given that each assessment of effort was specific to a given exam, residuals between each effort assessment and its corresponding exam score were allowed to covary. Overall, the model fit the data well by conventional standards of model fit: $\chi^{2}(28)=39.65$, $p=.071, \mathrm{CFI}=.99, \mathrm{RMSEA}=.04, \mathrm{SRMR}=.03$. Consistent with predictions, there was a significant indirect or mediated effect of Conscientiousness on exam performance through effort, $\beta=.12$,

5. Analyses substituting total course points for exam scores functioned similarly to the reported analyses for the current and subsequent analyses. 


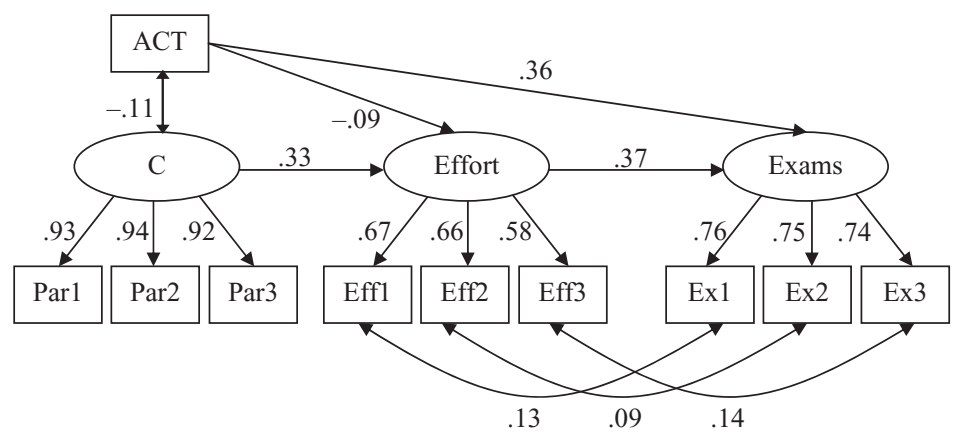

Figure 2

Mediation of Conscientiousness to exam performance by exam-specific effort. C = Conscientiousness; $\mathbf{P a r}=$ parcel indicator; Eff $=$ effort indicator; $E x=$ exam indicator. $\chi^{2}(28)=39.65, p=.071$, CFI $=.99$, RMSEA $=.04$, SRMR $=.03$. All effects are standardized, and all $\beta$ s (except for the correlation between ACT and C and the effect from ACT to exam effort) are statistically significant $(p<.05)$.

$S E(\beta)=.035, t=3.50, p<.05$. Further, a model that included the direct effect from Conscientiousness to exam performance did not fit the data significantly better than the current model, $\Delta \chi^{2}(1)=.26$, $n s$, providing support for full mediation instead of partial mediation. Interestingly, ACT had a direct effect on exam performance that was almost completely independent of the effect of Conscientiousness through effort. In other words, exam performance was predicted by both cognitive (ACT) and noncognitive (Conscientiousness and effort) pathways.

To consider how the above results change when achievement goals are included in the model, we specified an extended model in which Conscientiousness predicts achievement goals (i.e., performance approach, performance avoidance, mastery approach, and mastery avoidance goals) and effort, achievement goals predict effort and exam performance, and effort predicts exam performance. Conscientiousness, effort, and exam scores were specified as in the previous model, and each of the achievement goals was a latent variable indicated by its three item responses (there were too few items to parcel). ACT scores were partialed out from all variables in the model, and achievement goal disturbances were allowed to covary with each other. The overall model had a more or less acceptable fit 
to the data, $\chi^{2}(183)=362.23, p<.001, \mathrm{CFI}=.94, \mathrm{RMSEA}=.05$, $\mathrm{SRMR}=.05$.

The majority of the misfit in the model seems to stem from the measurement portion of the model; a confirmatory factor analysis of the achievement goals did not have a particularly good fit to the data, $\chi^{2}(48)=143.52, p<.001, \mathrm{CFI}=.94, \mathrm{RMSEA}=.08, \mathrm{SRMR}=.06$. The largest modification index $(\mathrm{MI}=26.25)$ suggested that performance avoidance item three ("I just want to avoid doing poorly in this class") should be allowed to load (negatively) on the performance approach factor. Given that we used a well-established achievement goal measure, we decided not to include these suggested modifications, but the results of the analysis do not change if the suggested cross-loading is allowed.

To evaluate the proposed model linking Conscientiousness to academic outcomes, we examined the size and statistical significance of the various paths connecting Conscientiousness to exam performance. Similar to the models that follow, we followed up our confirmatory modeling approach with an exploratory modification by eliminating nonsignificant paths based on whether the biascorrected bootstrapped confidence interval for each coefficient contained zero. This approach made the final interpretation of the results much easier given that there were fewer pathways to interpret. However, our initial results are available upon request and in no way contradicted our final interpretations. Paths from Conscientiousness to performance and mastery avoidance goals; from performance approach, performance avoidance, and mastery avoidance goals to effort; and from mastery approach and avoidance goals to exam performance were small and statistically nonsignificant (all $|\beta|<.09$ ). Accordingly, they were removed from the final model.

Based on this final model, there are three main ways in which Conscientiousness is associated with exam performance (see Figure 3). First, Conscientiousness has a direct positive effect on effort levels, which then positively affect exam performance (indirect effect $\beta=.09, S E(\beta)=.037, t=2.36, p<.05)$. Second, Conscientiousness predicts mastery approach goal adoption, which in turn predicts increased effort and ultimately better performance (indirect effect $\beta=.05, \operatorname{SE}(\beta)=.024, t=2.19, p<.05)$. Finally, Conscientiousness is positively associated with performance approach goal adoption, which is associated with better exam scores (indirect effect $\beta=.04$, 


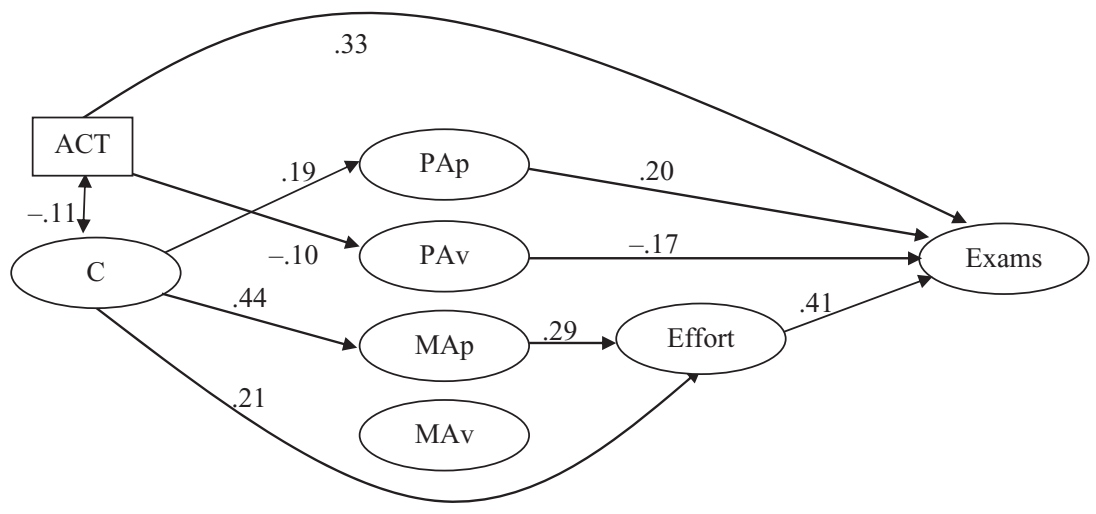

Figure 3

Mediation of Conscientiousness to exam performance by achievement goals and exam-specific effort. $\mathbf{C}=$ Conscientiousness; $\mathrm{PAp}=$ performance approach; $\mathrm{PAv}=$ performance avoid; $\mathrm{MAp}=$ mastery approach; $M A v=$ mastery avoid. $\chi^{2}(190)=367.95$, $p<.001$, CFI $=.95$, RMSEA $=.05$, SRMR $=.05$. All effects are standardized. ACT is allowed to relate to all variables in the model, but for simplicity, only statistically significant paths are shown $(p<.05)$, and covariation among the disturbances of the four achievement goals is not displayed.

$S E(\beta)=.013, t=2.97, p<.05)$. Taking all these paths together, the total effect of Conscientiousness on exam scores in this model was $\beta=.18, \operatorname{SE}(\beta)=.043, t=4.09, p<.05$. Similar to the previous model, effort was a relatively strong proximal predictor of exam performance, independent of ACT, but goal orientation predicted exam performance as well, both through effort (in the case of mastery approach goals) and independently of effort (in the case of performance approach and performance avoidance goals). It is noteworthy that Conscientiousness predicts both types of approach goals (but neither type of avoidance goals), suggesting that perhaps the potential positive outcomes that are of central concern to approach goaloriented individuals are also relevant for individuals with high levels of Conscientiousness.

Mediation by homework scores. We predicted that homework scores, as a behavioral indicator of effort, would also mediate the association between Conscientiousness and exam scores. The path model in Figure 4 displays the results of the structural equation 


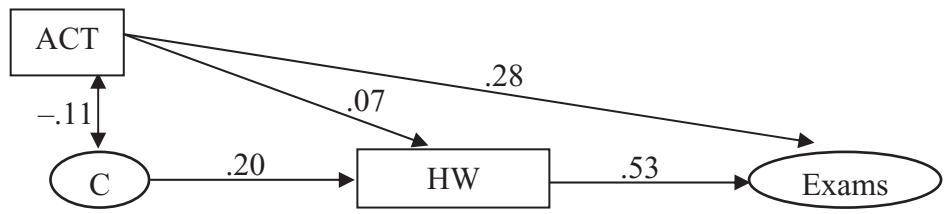

Figure 4

Mediation of Conscientiousness to exam scores by homework scores. $\mathrm{C}=$ Conscientiousness; $\mathrm{HW}=$ homework. $\chi^{2}(17)=22.04$, $p=.183$, CFI $=1.00$, RMSEA $=.03$, SRMR $=.03$. All effects are standardized, and all $\beta$ s with absolute value $>.11$ are statistically significant $(p<.05)$. For simplicity, latent variable indicators and loadings are not displayed.

analysis. Overall, the model fit the data well, $\chi^{2}(17)=22.04, p=.183$, $\mathrm{CFI}=1.00, \mathrm{RMSEA}=.03, \mathrm{SRMR}=.03$, and there was a statistically significant indirect effect of Conscientiousness on exam scores via homework scores, $\beta=.11, S E(\beta)=.026, t=4.13, p<.05$. A model with the direct effect from Conscientiousness to exam scores included did not fit the data significantly better than the current model, $\Delta \chi^{2}(1)=0.80, n s$.

We conducted a similar analysis including achievement goals in the model (as above). The model had an acceptable fit to the data, again by conventional standards of model fit: $\chi^{2}(145)=287.12$, $p<.001$, CFI $=.96$, RMSEA $=.05$, SRMR $=.05$. We again computed bias-corrected bootstrapped confidence intervals and eliminated statistically nonsignificant paths from the model. The paths from Conscientiousness to performance and mastery avoidance goals, from mastery approach and mastery avoidance goals to homework, and all of the paths from the achievement goals to exam scores were not statistically significant, with the absolute value of all $\beta s<.13$. Therefore we reestimated the model with these paths removed.

This model results in two statistically significant routes by which Conscientiousness predicts exam scores (see Figure 5). First, Conscientiousness is positively associated with homework scores, which then positively predict exam scores (indirect effect $\beta=.09$, $S E(\beta)=.029, t=2.91, p<.05)$. Second, Conscientiousness is positively associated with performance approach goals, which positively predict homework scores, which are in turn positively associated with exams (indirect effect $\beta=.02, S E(\beta)=.009, t=2.34, p<.05$ ). 


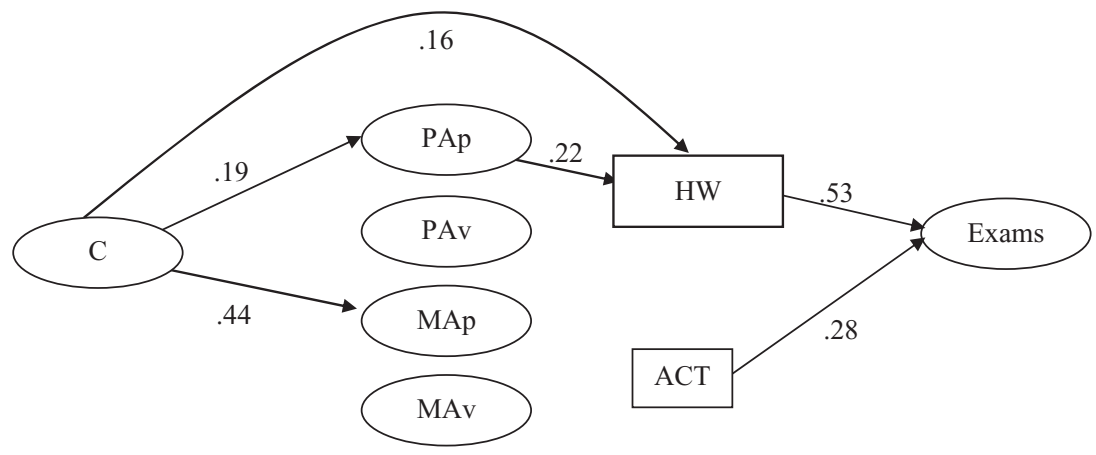

Figure 5

Mediation of Conscientiousness to exam scores by achievement goals and homework scores. $\mathbf{C}=$ Conscientiousness; PAp $=$ performance approach; PAv = performance avoid; MAp = mastery approach; $\quad \mathrm{MAv}=$ mastery avoid; $\mathrm{HW}=$ homework. $\quad \chi^{2}(154)=$ 303.92, $p<.001, \mathrm{CFI}=.95$, RMSEA $=.05, \mathrm{SRMR}=.06$. All effects are standardized. For simplicity, latent variable indicators and loadings are not displayed. ACT is associated with everything in the model, but for simplicity, only statistically significant paths $(p<.05)$ are shown, and covariation among achievement goal disturbances is not displayed.

Together, the total effect of Conscientiousness on exam scores was $\beta=.11, \operatorname{SE}(\beta)=.030, t=3.59, p<.05$.

Mediation by study strategies. To examine the question of how study strategies mediate the association between Conscientiousness and performance outcomes, we conducted a series of regression analyses with each of the three academic performance outcomes as the dependent variable and ACT score, the Big Five factors, and the four study strategies as independent variables. The addition of the study strategies in Step 2 nearly doubled the total variance explained in total points, exams, and the course paper outcomes (Table 3), with increases of $11 \%, 15 \%$, and $4 \%$, respectively). Further, the effect of Conscientiousness on the outcome variables became statistically nonsignificant when study strategies were added in Step 2. This analysis provides preliminary evidence that study strategies are fully mediating the effect of Conscientiousness on performance. However, it should be noted that surface processing and deep processing are not associated with either total points or exam scores (consistent 
Table 3

Regression of Performance Measures on Personality Variables and Study Strategies

\begin{tabular}{|c|c|c|c|c|c|c|c|c|c|}
\hline \multirow[b]{2}{*}{ Variable } & \multicolumn{3}{|c|}{ Total Points } & \multicolumn{3}{|c|}{ Exams } & \multicolumn{3}{|c|}{ Course Paper } \\
\hline & $\beta$ & $S E$ & $t$ & $\beta$ & $S E$ & $t$ & $\beta$ & $S E$ & $t$ \\
\hline \multicolumn{10}{|l|}{ Step 1} \\
\hline ACT & .23 & 1.28 & 3.69 & .29 & .20 & 4.78 & .18 & .41 & 2.75 \\
\hline $\mathrm{E}$ & -.02 & 5.56 & -.36 & -.11 & .88 & -1.73 & .00 & 1.82 & .00 \\
\hline A & -.05 & 8.53 & -.74 & .00 & 1.35 & .04 & -.01 & 2.74 & -.20 \\
\hline $\mathrm{C}$ & .26 & 9.22 & 3.93 & .15 & 1.46 & 2.32 & .16 & 2.98 & 2.31 \\
\hline $\mathrm{N}$ & .05 & 5.82 & .82 & -.02 & .92 & -.29 & .11 & 1.87 & 1.60 \\
\hline $\mathrm{O}$ & .06 & 7.32 & .34 & .06 & 1.16 & .90 & -.03 & 2.39 & -.40 \\
\hline$R^{2}$ & & .11 & & & .13 & & & .05 & \\
\hline \multicolumn{10}{|l|}{ Step 2} \\
\hline $\mathrm{ACT}$ & .21 & 1.23 & 3.57 & .27 & .19 & 4.74 & .18 & .41 & 2.76 \\
\hline $\mathrm{E}$ & -.03 & 5.30 & -.44 & -.11 & .82 & -1.82 & -.01 & 1.80 & -.12 \\
\hline A & -.07 & 8.19 & -1.11 & -.02 & 1.27 & -.29 & -.03 & 2.76 & -.46 \\
\hline $\mathrm{C}$ & .09 & 9.65 & 1.28 & -.04 & 1.49 & -.57 & .09 & 3.24 & 1.14 \\
\hline $\mathrm{N}$ & .10 & 5.81 & 1.53 & .05 & .90 & .45 & .11 & 1.96 & 1.49 \\
\hline $\mathrm{O}$ & .04 & 7.27 & .58 & .02 & 1.13 & .76 & -.03 & 2.47 & -.39 \\
\hline Surface processing & .03 & 6.53 & .52 & -.03 & 1.01 & -.43 & .19 & 2.21 & 2.54 \\
\hline Deep processing & .00 & 5.90 & .04 & .02 & .91 & .25 & .01 & 1.98 & .17 \\
\hline Disorganization & -.20 & 4.53 & -3.01 & -.24 & .70 & -3.76 & -.08 & 1.55 & -1.05 \\
\hline Tenacity & .25 & 6.88 & 3.30 & .31 & 1.06 & 4.14 & .01 & 2.34 & .13 \\
\hline$R^{2}$ & & .22 & & & .27 & & & .09 & \\
\hline$\Delta R^{2}$ & & .11 & & & .14 & & & .04 & \\
\hline$d f$ & & 266 & & & 266 & & & 257 & \\
\hline
\end{tabular}

Note. Boldfaced coefficients are statistically significant $(p<.05) . \mathrm{E}=$ Extraversion; $\mathrm{A}=$ Agreeableness; $\mathrm{C}=$ Conscientiousness; $\mathrm{N}=$ Neuroticism; $\mathrm{O}=$ Openness.

with Elliot, McGregor, \& Gable, 1999, Studies 1 and 2). Therefore, in subsequent analyses, we focus on the study strategies of tenacity and disorganization. Regarding the latter, note that "organization" would be considered a more apt label for a study strategy, but we refer to the construct of "disorganization" to be consistent with the name of the scale that is used.

To test an overall process model connecting Conscientiousness to course performance via achievement goals and study strategies as conceptualized in Figure 1, we fit a structural equation 
model with several theoretical routes from Conscientiousness to performance. First, we tested for mediated effects from Conscientiousness to exam scores, with effects going first through the four achievement goals and then through tenacious and disorganized study strategies. We also allowed for direct effects from the four achievement goals to exam scores, as well as direct effects from Conscientiousness to tenacious and disorganized study strategies. Disturbances of the four achievement goals were allowed to covary with each other (six parameters), and the disturbance of tenacity was allowed to covary with the disturbance of disorganization (one parameter). ACT score was also partialed out from all variables to demonstrate a theoretical model involving motivational effects.

An initial examination of the model revealed that it fit the data well by all conventional model fit indices: $\chi^{2}(157)=299.98$, $p<.001, \mathrm{CFI}=.96, \mathrm{RMSEA}=.05, \quad \mathrm{SRMR}=.05$. To improve clarity and increase parsimony, the model was modified by trimming the statistically nonsignificant paths that were identified via the same procedure performed in the previous analyses. Namely, the paths from Conscientiousness to performance avoidance and mastery avoidance goals were small and not statistically significant ( $\beta \mathrm{s}=.06$ and -.09 , respectively) and were trimmed. Additionally, the only achievement goal that loaded on tenacious study strategies was mastery approach goals (all trimmed $|\beta|<.10$ ), and the only achievement goal that loaded on disorganized study strategies was mastery avoidance goals (all trimmed $|\beta|<.11$ ). Thus, with the exception of the paths from mastery approach goals to tenacious study strategies and mastery avoidance goals to disorganized study strategies, all paths from the achievement goals to study strategies were removed. Finally, the direct effect from mastery approach goals to exams was not statistically significant $(\beta=-.14)$ and was trimmed.

Next, the mediated or indirect effects from Conscientiousness to exam scores were examined (Figure 6). The sum of the indirect effects through study strategies was $\beta=.24, S E(\beta)=.039, t=6.15$, $p<.05$, indicating that as a whole, the mediators explained a statistically significant portion of the association between Conscientiousness and performance. Breaking down the indirect effect into its individual components, it can be seen that the path from Conscientiousness to exam scores through disorganization was $\beta=.11$, 


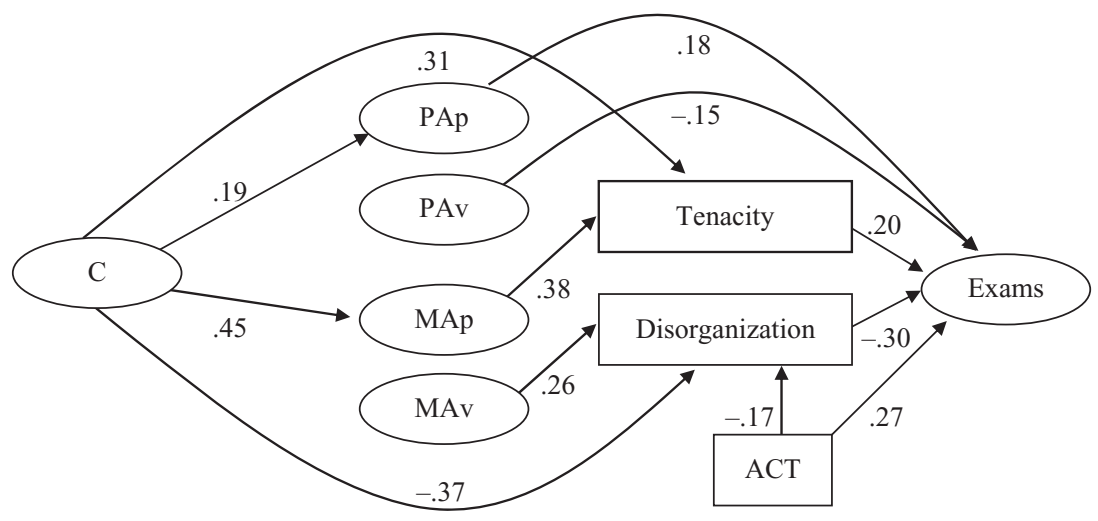

Figure 6

Mediation of Conscientiousness to total course points by achievement goals and study strategies. C=Conscientiousness; $\mathrm{PAp}=$ performance approach; $\mathrm{PAv}=$ performance avoid; $\mathrm{MAp}=$ mastery approach; $M A v=$ mastery avoid. $\chi^{2}(166)=317.06$, $p<.001$, CFI $=.95$, RMSEA $=.05$, SRMR $=.06$. For simplicity, latent variable indicators and covariation among achievement goal disturbances and between study strategy disturbances are not displayed. ACT is associated with all variables in the model, but only statistically significant paths $(p<.05)$ involving ACT are displaryed. The effect of mastery avoidance goals on exam scores was statistically significant in the initial model, but not in the final model $(\beta=.10)$, so its effect is included in the model but is not displayed here.

$S E(\beta)=.028, t=3.96, p<.05$, and the path from Conscientiousness to exam scores through tenacity was $\beta=.06, S E(\beta)=.023, t=2.57$, $p<.05$, showing that there was a statistically significant effect of Conscientiousness on performance that occurred independent of any association with achievement goals. There was also some portion of the effect that traveled through achievement goals. The path from Conscientiousness to exam scores through performance approach goals was $\beta=.04, S E(\beta)=.015, t=2.35, p<.05$, and the path from Conscientiousness to exam scores through mastery approach goals and then tenacity was $\beta=.03, S E(\beta)=.013, t=2.67, p<.05$. Thus, as in the analyses presented previously, the majority of the indirect effect on performance traveled from Conscientiousness directly through effortful strategies, but a small portion of the effect was mediated through approach achievement goals. 


\section{GENERAL DISCUSSION}

Decades of research support the general notion that Conscientiousness is positively associated with performance in academic and employment settings. The goal of the current research was to evaluate a more specific model of the psychological processes helping to explain this general bivariate association, in particular by showing that Conscientiousness predicts performance because Conscientiousness contributes to setting achievement-related goals and to engaging in effortful strategies. We also demonstrated that the facets of Conscientiousness varied in their predictive power, with Self-Discipline being the strongest and most consistent predictor of course effort and course performance. Taken together, these results suggest that Conscientiousness in general, and Self-Discipline in particular, contribute to the ability to plan academic goals and to channel effort and persistence in the pursuit of those goals (e.g., effort in homework and exam preparation), which in turn promote success in achievementrelated contexts (e.g., high exam scores, high course GPA). Our empirical results are therefore consistent with our guiding hypotheses about the specific processes linking Conscientiousness to achievement-related outcomes.

Regarding the role of goal orientation in our theoretical process model, both mastery and performance approach achievement goals mediated part of the association between Conscientiousness and effortful strategies. However, mastery approach goals seemed to be particularly important in this process, as the associations between Conscientiousness and mastery approach goals were about twice the size of similar associations with performance approach goals ( $\beta \mathrm{s}=$ about .44 vs. .19, respectively, across analyses). This finding is consistent with the notion that mastery approach goals pertain to self-improvement more than performance approach goals (Elliot \& McGregor, 2001), and therefore they have more effort-related content. Thus, our results provide support for the ideas that increased use of effortful strategies, as well as higher levels of approach-related achievement goals, explain why Conscientiousness is associated with performance. Nonetheless, the effect sizes linking Conscientiousness with achievement goals were generally smaller than effect sizes linking Conscientiousness with effortful strategies. This may explain why Conscientiousness has not played a more prominent role in existing theorizing about the connections between 
dispositional tendencies and achievement goals (e.g., Elliot \& Thrash, 2010). However, we believe that future research should continue to try to integrate theory on traits and goals in order to better clarify the similarities and differences between these two constructs. A plethora of high-quality research on traits and goals is currently being conducted independently by personality and social-cognitive scholars, and there remains much integration to be done across these two research traditions.

\section{Limitations}

Although we believe that the present results provide interesting and important support for hypotheses about the processes linking Conscientiousness with performance outcomes, there are several caveats and limitations worth noting. Many of the measures used in this study were self-reported, and there are ongoing concerns about the limits of self-report measures. Moreover, the self-report measure of effort in exam preparation had particular limitations. This measure was taken directly after each of the three exams, so students probably had a subjective sense of how well they did on the exam although they did not yet know their actual score. Students' retrospective assessment of their effort in preparing for the exam may have therefore been influenced by their current feelings about their exam performance. Although it would have been better to administer this measure just prior to students taking their exams, we decided that this was not feasible or particularly ethical because administering questionnaires immediately prior to an exam might interfere with performance given the time constraints of exams. Our design decision in this respect was made on practical grounds and with an eye toward keeping disruptions of the exam process to a minimum. We therefore urge caution in interpreting results relying on this measure; however, it is notable that these results follow the same pattern as those using other effort mediators (i.e., homework scores and effortful study strategies).

Another potential concern involves the simultaneous measurement of personality traits and achievement goals. Certainly, a stronger model of the hypothesized mediating process would have included, first, temporal separation between predictors (personality traits) and mediators (achievement goals) and second, the measurement of predictors, mediators, and outcomes at all points in time in 
order to rule out reverse causality (D. A. Cole \& Turner, 1993). Our treatment of traits and goals is consistent at a theoretical level with the specifications of the hierarchical model of motivation. Nonetheless, future research should demonstrate temporal precedence in order to empirically verify these theoretical assumptions. Indeed, the line between traits and goals is often fuzzy, and for this reason, we advocate continued work on the relations between these two constructs.

Care should also be taken when generalizing the results beyond the current research context. The current research is notable for its multi-measure, multi-wave design, but it was conducted using primarily upper-division college students and findings may not replicate in other educational settings (e.g., elementary or secondary classrooms), other college courses, or the workplace. For instance, the content of the current course was generally cumulative, and the topic is not always popular with students. The ability to focus attention and work hard therefore seemed to be key ingredients for success. Thus, this course in particular may have been a good context for studying how Conscientiousness is linked with academic outcomes. At a broader level, components of classroom structure may influence the way that traits are expressed.

\section{CLOSING THOUGHTS}

In conclusion, the current results provide broad evidence for the importance of effort as a motivational mechanism that explains the association between Conscientiousness and academic performance. In addition, beyond informing our knowledge of psychological mechanisms, these findings suggest that effortful strategies may serve as a logical target for academic interventions. Effortful strategies are more malleable than traits and have more direct or proximal influences on outcomes compared to personality and temperamental factors. Providing structure and reinforcement for students to complete all of their homework or to increase how much time they spend preparing for exams, for instance, might translate into higher levels of academic performance more readily than more global and often vague instructions to become more self-disciplined. This conjecture is certainly aligned with a similar notion in the goal-setting literature (e.g., Locke \& Latham, 2002) that goal attainment is enhanced when 
difficult and specific goal levels are assigned versus vague do-yourbest strategies, because the former focuses and directs attention, allowing for better feedback and self-monitoring.

Indeed, an important question for future research is whether interventions aimed at increasing effortful strategies would work, and if they do work, whether they work to the same degree for all individuals. It might be the case that such direct interventions only help to promote achievement for those low in Conscientiousness. The idea is that individuals higher in this disposition are already doing what the intervention prescribes. Alternatively, it might be that effortful strategies only work well for individuals high in Conscientiousness, where in a sense, "the rich get richer," and the intervention would be ineffective for those low in Conscientiousnessother strategies should be developed that would work better for them. Clearly, more research is needed to determine the answer to these and other interesting questions regarding the nature and effectiveness of interventions that improve academic performance and success. However, we suggest that a focus on individual differences is likely to prove useful for intervention efforts. To be sure, we suspect that systematic research that continues to investigate what conscientious people naturally do to succeed in achievement-related contexts will provide clues as to the targets of interventions designed to promote success.

\section{REFERENCES}

ACT. (2007). The ACT technical manual. Iowa City, IA: Author.

Barrick, M. R., \& Mount, M. K. (1991). The Big Five personality dimensions and job performance: A meta-analysis. Personnel Psychology, 44, 1-26.

Barrick, M. R., Stewart, G. L., \& Piotrowski, M. (2002). Personality and job performance: Test of the mediating effects of motivation among sales representatives. Journal of Applied Psychology, 87, 43-51.

Charmorro-Premuzic, T., \& Furnham, A. (2003). Personality predicts academic performance: Evidence from two longitudinal university samples. Journal of Research in Personality, 37, 319-338.

Cole, D. A., \& Turner, J. E., Jr. (1993). Models of cognitive mediation and moderation in childhood depression. Journal of Abnormal Psychology, 102, 271-281.

Cole, J. S., \& Gonyea, R. M. (2010). Accuracy of self-reported SAT and ACT test scores: Implications for research. Research in Higher Education, 51, 305319. 
Cooper, H., Robinson, J. C., \& Patall, E. A. (2006). Does homework improve academic achievement? A synthesis of research, 1987-2003. Review of Educational Research, 76, 1-62.

Costa, P. T., Jr., \& McCrea, R. R. (1992). Revised NEO personality inventory (NEO PI-R) and NEO five-factor inventory (NEO-FFI). Odessa, FL: Psychological Assessment Resources.

DeYoung, C. G., Hirsh, J. B., Shane, M. S., Papademtris, X., Rajeevan, N., \& Gray, J. R. (2010). Testing predictions from personality neuroscience: Brain structure and the Big Five. Psychological Science, 21, 820-828.

De Vries, A., De Vries, R. E., \& Born, M. Ph. (2010). Broad versus narrow traits: Conscientiousness and honesty-humility as predictors of academic criteria. European Journal of Personality, 25, 336-348.

Duckworth, A. L., \& Seligman, M. E. P. (2005). Self-discipline outdoes IQ in predicting academic performance of adolescents. Psychological Science, 16, 939-944.

Dweck, C. S., \& Leggett, E. L. (1988). A social-cognitive approach to motivation and personality. Psychological Review, 95, 256-273.

Elliot, A. J. (2006). The hierarchical model of approach-avoidance motivation. Motivation and Emotion, 30, 111-116.

Elliot, A. J., \& Church, M. A. (1997). A hierarchical model of approach and avoidance achievement motivation. Journal of Personality and Social Psychology, 72, 218-232.

Elliot, A. J., \& McGregor, H. A. (2001). A $2 \times 2$ achievement goal framework. Journal of Personality and Social Psychology, 80, 501-519.

Elliot, A. J., McGregor, H. A., \& Gable, S. L. (1999). Achievement goals, study strategies, and exam performance: A mediational analysis. Journal of Educational Psychology, 91, 549-563.

Elliot, A. J., \& Thrash, T. M. (2002). Approach-avoidance motivation in personality: Approach and avoidance temperaments and goals. Journal of Personality and Social Psychology, 82, 804-818.

Elliot, A. J., \& Thrash, T. M. (2010). Approach and avoidance temperament as basic dimensions of personality. Journal of Personality, 78, 865-906.

Goldberg, L. R. (1999). A broad-bandwidth, public domain, personality inventory measuring the lower-level facets of several five-factor models. In I. Mervielde, I. Deary, F. De Fruyt, \& F. Ostendorf (Eds.), Personality psychology in Europe (Vol. 7, pp. 7-28). Tilburg, The Netherlands: Tilburg University Press.

Hofmann, W., Gschwendner, T., Friese, M., Wiers, R. W., \& Schmitt, M. (2008). Working memory capacity and self-regulatory behavior: Toward an individual differences perspective on behavior determination by automatic versus controlled processes. Journal of Personality and Social Psychology, 95, 962977.

Jackson, D. N. (1984). Personality Research Form manual. Port Huron, MI: Research Psychologists Press.

John, O. P., Naumann, L. P., \& Soto, C. J. (2008). Paradigm shift to the integrative Big Five trait taxonomy: History, measurement, and conceptual issues. In O. P. John, R. W. Robins, \& L. A. Pervin (Eds.), Handbook of personality: Theory and research (3rd ed., pp. 265-286). New York: Guilford Press. 
Judge, T. A., Higgins, C. A., Thoresen, C. J., \& Barrick, M. R. (1999). The Big Five personality traits, general mental ability, and career success across the life span. Personnel Psychology, 52, 621-652.

Judge, T. A., Klinger, R., Simon, L. S., \& Yang, I. W. F. (2008). The contributions of personality to organizational behavior and psychology: Findings, criticisms, and future research directions. Social and Personality Psychology Compass, 2, 1982-2000.

Keith, T. Z., \& Cool, V. A. (1992). Testing models of school learning: Effects of quality of instruction, motivation, academic coursework, and homework on academic achievement. School Psychology Quarterly, 7, 207-226.

Keith, T. Z., Diamond-Hallam, C., \& Fine, J. G. (2004). Longitudinal effects of in-school and out-of-school homework on high school grades. School Psychology Quarterly, 19, 187-211.

Kishton, J. M., \& Widaman, K. F. (1994). Unidimensional versus domain representative parceling of questionnaire items: An empirical example. Educational and Psychological Measurement, 54, 757-765.

Kochanska, G., \& Knaack, A. (2003). Effortful control as a personality characteristic of young children: Antecedents, correlates, and consequences. Journal of Personality, 71, 1087-1112.

Locke, E. A., \& Latham, G. P. (2002). Building a practically useful theory of goal setting and task motivation: A 35-year odyssey. American Psychologist, 57, 705-717.

MacKinnon, D. P., Fairchild, A. J., \& Fritz, M. S. (2007). Mediation analysis. Annual Review of Psychology, 58, 593-614.

McAdams, D. P., \& Pals, J. L. (2006). A new Big Five: Fundamental principles for an integrative science of personality. American Psychologist, 61, 204217.

McCrae, R. R., \& Costa, P. T., Jr. (2008). Empirical and theoretical status of the five-factor model of personality traits. In G. Boyle, G. Matthews, \& D. H. Saklofske (Eds.), The SAGE handbook of personality theory and assessment (pp. 273-294). Thousand Oaks, CA: Sage.

Muthén, L. K., \& Muthén, B. O. (1998-2006). Mplus user's guide (4th ed.). Los Angeles: Author.

Nigg, J. T. (2000). On inhibition/disinhibition in developmental psychopathology: Views from cognitive and personality psychology and a working inhibition taxonomy. Psychological Bulletin, 126, 220-246.

Noftle, E. E., \& Robins, R. W. (2007). Personality predictors of academic outcomes: Big Five correlates of GPA and SAT scores. Journal of Personality and Social Psychology, 93, 116-130.

O’Connor, M. C., \& Paunonen, S. V. (2007). Big Five personality predictors of post-secondary academic performance. Personality and Individual Differences, 43, 971-990.

Ones, D. S., \& Viswesvaran, C. (1996). Bandwidth-fidelity dilemma in personality measurement for personnel selection. Journal of Organizational Behavior, 17, 609-626.

Paunonen, S. V., \& Ashton, M. C. (2001). Big Five predictors of academic achievement. Journal of Research in Personality, 35, 78-90. 
Payne, S. C., Youngcourt, S. S., \& Beaubien, J. M. (2007). A meta-analytic examination of the goal orientation nomological net. Journal of Applied Psychology, 92, 128-150.

Roberts, B. W., Kuncel, N. R., Shiner, R., Caspi, A., \& Goldberg, L. R. (2007). The power of personality: The comparative validity of personality traits, socioeconomic status, and cognitive ability for predicting important life outcomes. Perspectives on Psychological Science, 2, 313-345.

Schmidt, F. L., \& Hunter, J. E. (1998). The validity and utility of selection methods in personnel psychology: Practical and theoretical implications of 85 years of research. Psychological Bulletin, 124, 262-274.

Staff, J., Schulenberg, J. E., \& Bachman, J. G. (2010). Adolescent work intensity, school performance, and academic engagement. Sociology of Education, 83, 183-200.

Trautwein, U., Lüdtke, O., Roberts, B. W., Schnyder, I., \& Niggli, A. (2009). Different forces, same consequence: Conscientiousness and competence beliefs are independent predictors of academic effort and achievement. Journal of Personality and Social Psychology, 97, 1115-1128.

Widaman, K. F. (2006). Missing data: What to do with or without them. Monographs of the Society for Research in Child Development, 71, 42-64. 


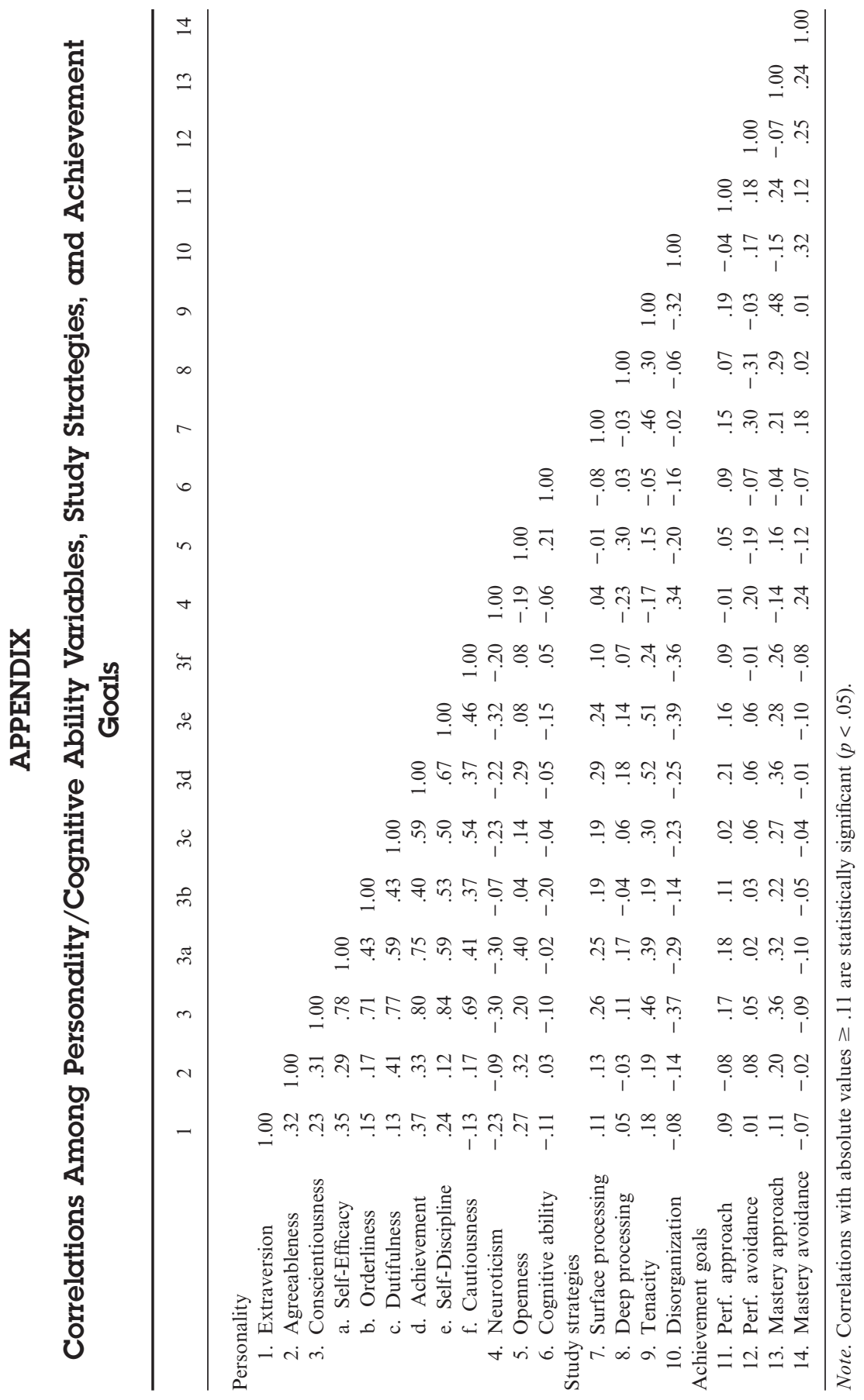

